\title{
谈河道管理存在的问题及生态治理建议
}

\author{
吴民仙 \\ 僓州市柯城区水利局 \\ DOI:10.32629/hwr.v3i4.2042
}

[摘 要] 在新时期国家发展战略中, 环境问题已经成为国家重点关注的国家发展问题之一, 在众多的生态问题之中, 河道生态 问题是其中的重要组成部分, 虽然当前在政策要求下已经积极开展相关的河道生态治理工作,但是由于经验尚浅技术不佳,绝 大多数的河道管理工作都没有起到有效的生态治理作用,河道的生态治理工作是一项系统性科学性的综合工作,我们在进行相 关工作的过程中必须了解造成河道生态问题的相关影响因素并根据科学的手段来积极进行治理,就此问题本文将展开具体的 分析并提出相关建议。

[关键词] 河道管理; 生态问题; 治理建议

我们分析河道管理中存在的问题及生态治理的相关建 议, 首先就要明确河道管理的作用和目的, 我们在进行相关 工作研究的过程中一定要明确相关问题的产生原因, 河道管 理中不仅涉及到相关防洪防汛工作, 同时也包含河道生态治 理的内容, 我们在本文中重点要研究的是河道管理过程中存 在的生态问题及相关的治理意见, 那么我们的研究方向就应 该倾向于河道管理过程中生态问题的影响因素, 并且对于河 道管理中的相关防洪防汛问题进行简述, 并根据这些影响因 素去制定相应的治理方案。

\section{1 河道管理存在的问题}

\section{1 人为因素问题}

对于河道管理工作一直比较倾向于建立完善的防洪防 汛体系, 虽然投入较多建设资金来完善相应的河道防洪防汛 工程, 但是从整体上来讲的河道防洪防汛能力还较为薄弱, 面对水量激增的情况还是容易造成较大的洪汛灾害。我国国 土面积辽阔, 内陆地区水系分布复杂, 河道交错, 所以在相关 防洪汛工程上的投入虽然总体来讲比较多, 但仍存在分布不 均衡的现象, 这是其防洪汛功能存在问题的主要原因。由于 河道数量多分布复杂, 所以我们在进行相关河道工程建设的 过程中总是需要较大的工程建设量, 这种情况造成了河道原 有生态环境的破坏, 首先是工程建设过程中河道两岸的植物 遭到了破坏, 土地一旦失去了相关植被的巩固, 就会发生水 土流失的现象, 大量的岸边土基进入到河道之内, 不仅让河 道变宽, 同时也增加了河道内的泥沙量, 随着泥沙量的不断 增多, 河床位置不断升高, 淤泥量也不断增加, 造成相应的生 态问题 ${ }^{[1]}$ 。同时, 河道生态人为排放污染问题也是河道管理 中存在的重要问题。随着经济不断发展, 城市和农村的发展 速度都在不断提升, 更好的社会背景让水资源污染现象也越 来越严重, 随着工业废水、生活废水以及农业生产养殖中的 各种污染物不断进入河流, 河道水体质量严重下降, 河水的 组成成分遭到破坏, 这种情况造成了严重的河道生态环境问 题, 不仅水生动物大量死亡, 同时水生生物也由于各种化学 物质的影响变得非常不稳定, 这对于河道生态系统的持续发
展非常不利。同时, 随着人类建设发展的需求, 我们擅自改变 河道原有情况来满足使用和施工需求仿佛已经变得非常普 通, 举一个非常具有实际探究意义的例子: 某地山流经辖区 虽然只有 8 公里多, 却有三家企业在没有采砂证的情况下非 法挖沙, 直接导致当地耕地大面积流失, 仅去年一年, 就有 15 亩耕地被河水吞没, 大量的挖沙作业不仅让河道原有走向发 生改变, 同时也让水生态环境受到了严重污染, 这种非法挖 沙活动不仅对河道相关生态环境造成了破坏, 同时也让河道 两侧的农业耕地受到了严重影响, 北岸的小麦种植地下方已 经被掏空, 土地整体下陷非常严重, 这些小麦虽然现在长势 较好但是成熟后却存在收割困难的问题, 不仅人员作业存在 危险, 而且大型收割机械无法在这种情况下进行收割, 造成 了严重的经济及生态危害 ${ }^{[2]}$ 。

\section{2 自然因素问题}

近些年来自然灾害频发, 这对于河道水环境整体影响是 非常严重的, 我们在进行自然因素问题研究的过程中, 重点 要从河道生态系统和河道当前状态来分析, 自然因素对河道 生态系统的影响主要是降低了水生态系统整体的自净能力, 而众多河道当前都处于一种坡降逐渐变小的状态, 这种情况 改变了河道水体流动速度, 造成了水下泥沙的堆积, 泥沙堆 积形成了淤泥, 而淤泥正是水体生态环境的重要危害因素, 它不仅让水生植物不能正常生长, 同时也导致了水生动物 的生存困难 ${ }^{[3]}$ 。在自然匀速造成的问题中, 洪汛和干旱也是 重要的问题, 由于现阶段洪汛及干旱灾害时有发生, 这也导 致了河道生态系统遭到了破坏, 由于降水量过少, 一些河道 发生断流现象, 这对于原本水生态环境系统的影响是巨大 的, 干旱导致的河流断流让河床暴露于外界, 大量原有水生 生物死亡, 及时后续恢复河道的水体流动, 遭到破坏的生态 系统短时间内也难以恢复。而洪汛灾害则以非常强大的水 流速速和巨大的流经水量冲刷河道, 并且导致水体质量严 重下降, 这种影响也会给河道生态环境带来严重的问题, 不 仅大量水生生物的死亡, 同时也可能对河道原有结构路线 造成破坏 ${ }^{[4]}$ 。 


\section{2 河道生态治理建议}

2.1 健全河道管理制度

河道的生态问题与原有的管理制度缺陷之间有重要联 系, 我们在新时期必须重视河道管理制度的完善, 加强规章 制度及相关法律法规上对于河道治理的相关规范, 目前, 针 对河道治理问题, 我国已经出台了 “河长制”, 由各级党政主 要领导担任总河长, 负责对划归区域河湖的保护管理工作, 将管理责任和管理内容落实到明确的个人及单位, 这能够有 效缓解当前的河道生态问题现状, 同时, 在河道管理制度的 完善上, 我们还要注意相关工作单位的工作融合, 要在制度 上确立相关工作单位统筹规划共同治理共同负责的相关要 求, 在河道治理问题上进行综合管理, 对于人为污染排放要 强化监管处罚力度, 明确污水处理的重要性, 要在违规排污 的处罚力度上进行加强, 达到相关规范的执行效果, 同时, 要 科学利用河道资源, 严禁无证挖沙非法捕鱼等非法使用河道 资源的现象。在污染治理方面, 相关单位要切实发挥自身作 用, 在工作中做到对河道垃圾的清理工作, 一旦发现河道生 态问题要立刻解决, 充分重视相关工作对于地区可持续发展 的重要意义。

\section{2 加大综合治理的投入}

由于河道生态治理涉及部门众多, 需要接受监督管理的 企业和相关部门非常繁杂, 所以在治理过程中一定会存在较 大的资金投入, 这些支出不仅仅来源于相关的技术升级, 同 时也包括对各部门进行管理监督过程中的人工、设备及相关 的污水处理厂建设工程等费用, 治理河道生态系统恢复水域 的生态环境需要较多的资金投入, 我们一方面要争取政府资 金的追加, 同时也要广泛借助社会资源, 争取社会资金的进 入, 例如在进行污水处理厂的建设过程中, 我们就可以根据 分净化标准不同分别在相关工业厂区督促使用污水处理设 备, 在居民生活污水的处理上建立标准化的污水处理厂, 在 建设过程中应该充分利用污水处理设备的特殊性和今后运 行的常态化特点来吸引社会资源的进入, 一方面增加了设备 建设的社会效益, 同时也起到了良好的生态治理作用。

\section{3 尊重自然规律}

我们在进行河道生态治理的过程中, 一定要明确一个观
点, 那就是有效避免人为污染, 同时大力恢复河道生态系统, 在人为干预的情况下有效的减少污染排放同时强化河道自 身的生态系统恢复能力, 这首先需要我们减少人为污染进入 河道生态系统, 所以我们首先要从源头上严防污染, 减小人 类生活生产对于水生态系统的破坏, 同时建立湿地生态净化 区, 在强化周边生态系统的情况下同时加强自然生态系统对 于河道生态系统的净化作用, 湿地生态系统对于水污染有良 好的净化作用, 能够有效吸收水中过剩的化学营养物质, 恢 复水体正常的成分, 有效治理河道生态污染问题。

2.4 开展实际治理工作

在进行河道生态治理工作上我们首先应该对遭到破坏、 河道具体情况发生改变的相关区域进行修复, 如有因非法挖 沙等相关行为造成的河道宽度改变应该及时进行填土复原。 如水生植物遭到破坏应该及时进行弥补。河道宽度和河道其 他具体情况的改变在很大程度上会影响水域水流速度引起 相关生态环境的改变, 同时对水生植物造成影响, 进而引发 连锁反应导致河道生态系统遭到严重打击, 所以我们应该积 极恢复河道原有宽度及深度, 恢复水流速度, 充分改善水生 植物的生长情况, 从根源上改善河道生态状况。

\section{3 结束语}

在大力推进经济发展的过程中对于相关生态系统的破 坏是比较严重的, 在新时期确立了可持续发展的国策后, 我 们更应该重视相关生态环境的治理工作, 河道生态系统是生 态系统的重要组成部分, 我们要明确当前河道管理中存在的 问题, 并针对问题提出相关解决建议, 维护生态发展的健康 性, 切实保障可持续发展国策的有效实施。

\section{[参考文献]}

[1]谷俊芹.浅谈河道生态治理理念在山区中小河流治 理中的应用[J].建筑工程技术与设计,2016,(15):2039.

[2]王文松.分析河道管理中存在的问题及加强河道管理 的措施[J].建筑工程技术与设计,2018,(32):2104.

[3] 于维扬.水利工程河道治理存在问题及管理 [J].建筑 工程技术与设计,2018,(34):2458.

[4]盛光晓.河道管理存在的问题及生态治理建议 [J].建 材与装饰,2018,(51):288. 